\title{
The SENSIndoor FP7 Project: Main Results, Lessons Learned and Outlook
}

\author{
Andreas Schütze \\ Lab for Measurement Technology, Saarland University, Saarbrücken, Germany \\ schuetze@LMT.uni-saarland.de
}

\begin{abstract}
The FP7 project SENSIndoor "Nanotechnology-based intelligent multi-SENsor System with selective pre-concentration for Indoor air quality control" was initiated at the beginning of COST action EuNetAir and will come to its successful conclusion in December 2016. This contribution provides a short overview of the main results, but also lessons learned from the project outside of the scientific and technical achievements. These touch on the design and initiation of and collaboration within the project itself, but also on joining forces with other projects, especially for achieving better visibility for the addressed application and, thus, a greater impact of the project results. A brief outlook is also given on opportunities for further applications based on the SENSIndoor technology and beyond.
\end{abstract}

Key words: Indoor Air Quality, low-cost integrated sensor systems, sensitive and selective VOC detection, integrated micro-pre-concentrator, dissemination and exploitation

\section{Introduction}

Almost four years ago the SENSIndoor project partners started together on the path to developing novel, highly sensitive and uniquely selective VOC sensor systems for monitoring of Indoor Air Quality. The challenge was set by new regulations being announced in several countries, especially France, to reduce the level of hazardous volatile organic compounds (VOCs) in buildings. Target concentrations for formaldehyde and benzene were set to unprecedented low levels, down to below $1 \mathrm{ppb}$. Even though it was clear that even advanced laboratory analysis would be hard pushed to achieve these limits reliably, the partners set out to develop low-cost sensors systems for online monitoring. These systems would not only need to achieve unprecedented sensitivity, but also extremely high selectivity to discriminate between hazardous VOCs at ppb and sub-ppb levels and benign VOCs (cleaning agents, perfumes, alcohol vapor, etc.) at concentrations up to $1 \mathrm{ppm}$. The goal was to allow demand controlled ventilation (DCV) based on these sensor systems to reduce the energy consumption in modern buildings, but at the same time to ensure a healthy indoor environment.

To address this challenge, it was clear that we needed to bring together the best experts on sensor technologies for low concentrations and that we needed to address the complete technology chain from gas sensitive layers, trans- ducers, dynamic operation, advanced electronics to data analysis. But, we needed something more which led to the development of a novel pre-concentrator concept. Up until now, pre-concentration is used in many analytical systems, but only seldom in combination with gas sensors. In all of these applications, active pumping is used to control the flow of gas into and out of the pre-concentrator. However, even a micropump would lead to much higher power consumption and especially cost, which would be prohibitive for ubiquitous sensor systems for IAQ monitoring and DCV. Thus, we decided to develop a novel, integrated microsensor system with passive pre-concentrator based on gas transport by diffusion only. To achieve sufficient gas accumulation, metal organic framework (MOF) layers with huge internal surface areas would be integrated on micro hotplates, similar to those used for the gas sensors themselves. Furthermore, Pulsed Laser Deposition (PLD) was to be employed for deposition of gas sensitive layers with precisely tailored morphology and mass production compatibility.

These thoughts led to the formation of the project consortium shown in Fig. 1 and to the proposal that was eventually successful. Over the past almost three years the partners have succeeded in developing the various components and integrating them into sensor systems. These were successfully tested under controlled laboratory conditions and now, finally, also in realistic field test scenarios. 


\begin{tabular}{|c|c|}
\hline SENSIndoor & $\begin{array}{l}\text { Nanotechnology-based intelligent multi- } \\
\text { SENsor System with selective pre- } \\
\text { concentration for Indoor air quality control }\end{array}$ \\
\hline $\begin{array}{l}\text { UNIVERSITÄT } \\
\text { DES } \\
\text { SAARLANDES }\end{array}$ & $\begin{array}{l}\text { Universität des Saarlandes, Germany } \\
\text { Department of Mechatronics } \\
\text { Laboratory for Measurement Technology } \\
\text { Prof. Andreas Schütze }\end{array}$ \\
\hline Linköping University & $\begin{array}{l}\text { Linköping University, Sweden } \\
\text { Department of Physics, Chemistry and } \\
\text { Biology } \\
\text { Division of Applied Sensor Science } \\
\text { Prof. Anita Lloyd Spetz }\end{array}$ \\
\hline $\begin{array}{l}\text { UNIVERSITY of OULU } \\
\text { OUUUMYCopsTo }\end{array}$ & $\begin{array}{l}\text { University of Oulu, Finland } \\
\text { Functional Electroceramics Thin Film Group } \\
\text { Prof. Jyrki Lappalainen }\end{array}$ \\
\hline \#rau & $\begin{array}{l}\text { Fraunhofer Gesellschaft zur Förderung der } \\
\text { angewandten Forschung e.V., Germany } \\
\text { Fraunhofer Institute for Chemical Techno- } \\
\text { logy } \\
\text { Dr. Jürgen Hürttlen }\end{array}$ \\
\hline
\end{tabular}

\begin{tabular}{|c|c|}
\hline Picodeon & $\begin{array}{l}\text { Picodeon Ltd. Oy, Finland } \\
\text { Jari Liimatainen }\end{array}$ \\
\hline & $\begin{array}{l}\text { SGX Sensortech S.A., Switzerland } \\
\text { Dr. Christine Alépée }\end{array}$ \\
\hline Clean air sensors & $\begin{array}{l}\text { SenSiC AB, Sweden } \\
\text { Dr. Mike Andersson }\end{array}$ \\
\hline $\begin{array}{l}0^{\circ} \\
\text { Gas sensing } \\
\text { solutions }\end{array}$ & $\begin{array}{l}3 \mathrm{~S}-\text { Sensors, Signal processing, Systems } \\
\text { GmbH, Germany } \\
\text { Thorsten Conrad }\end{array}$ \\
\hline nanoSense & $\begin{array}{l}\text { NanoSense S.à.r.l., France } \\
\text { Olivier Martimort }\end{array}$ \\
\hline 2 & $\begin{array}{l}\text { European Research and Project Office } \\
\text { GmbH (Eurice), Germany } \\
\text { Corinna Hahn }\end{array}$ \\
\hline
\end{tabular}

Fig. 1. The SENSIndoor consortium, for further information visit www.sensindoor.eu.

\section{Main results}

This section will give a very brief overview over the main results, details can be found in the cited literature. PLD-based gas-sensitive layers for both MOS and SiC-FET gas sensors were developed demonstrating remarkable sensitivity and selectivity and achieving detection limits down to ppb and sub-ppb levels for our target gases even without any pre-concentration $[1,2]$.

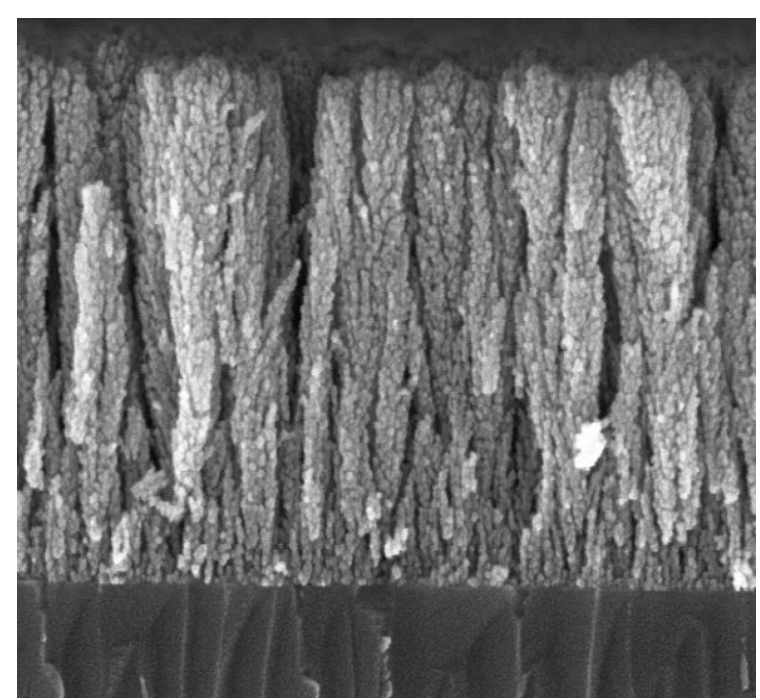

Fig. 2. PLD deposited $\mathrm{SnO}_{2}$ "nanotrees" demonstrating the potential for exact morphology control [1].

Novel SiC-based field effect transistor (FET) sensors for VOC detection were developed [2] and also the LTCC packaging technology necessary for their application. Optimized microhotplates were realized, not only for PLD-based metal oxide semiconductor (MOS) sensors (Fig. 4, [3]), but also for the novel pre-concentrator concept developed in the project [4].

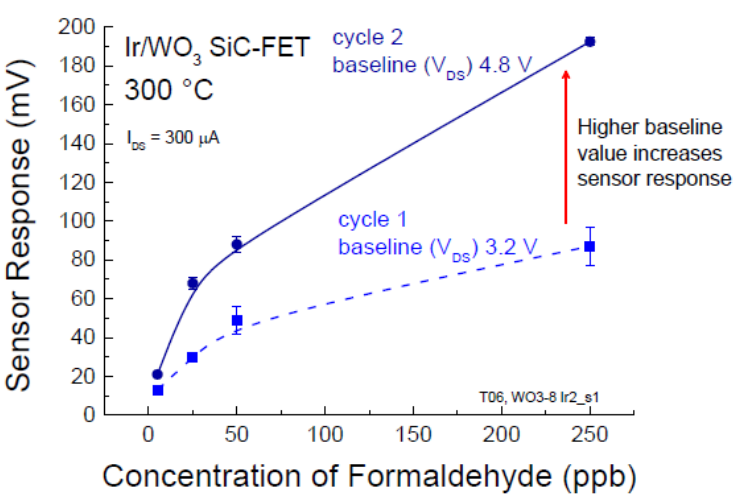

Fig. 3. Optimized SiC-FET sensors for detection of formaldehyde down to a few ppb.



Fig. 4. Optimized MOS sensors for selective detection of naphthalene down to a few ppb even against an ethanol background of 0.5 ppm [3].

MOF layers which allow boosting the sensitivity for the target VOCs further were developed to allow successful detection of extremely low target VOC concentrations not only under controlled lab conditions but also in the real ambient. Novel test methods and systems for 
reproducible testing of sensors and sensor systems with complex VOC mixtures down to sub-ppb levels were established [5]. Dynamic operating modes were developed for both MOS (Fig. 5) and SiC-FET sensor systems [6-10].

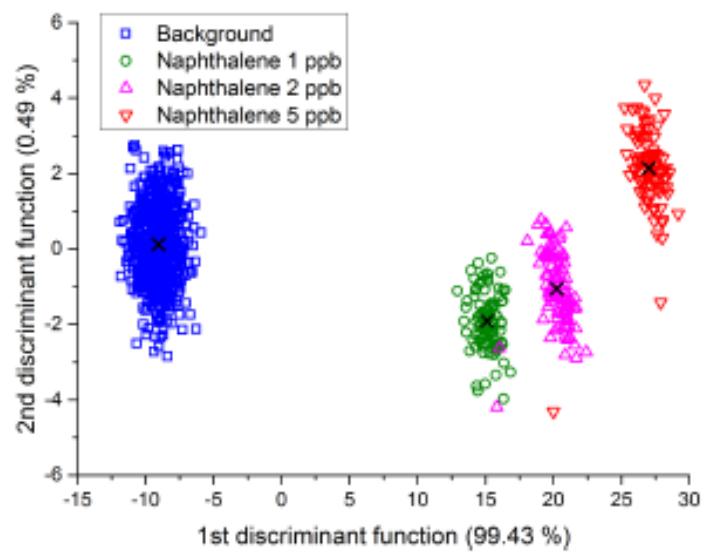

Fig. 5. Dynamic MOS sensor operation allowing quantification of target VOCs at ppb level [3].

Highly integrated electronics for sensor system operation and read-out combining high performance and low cost were realized, Fig. 6 .
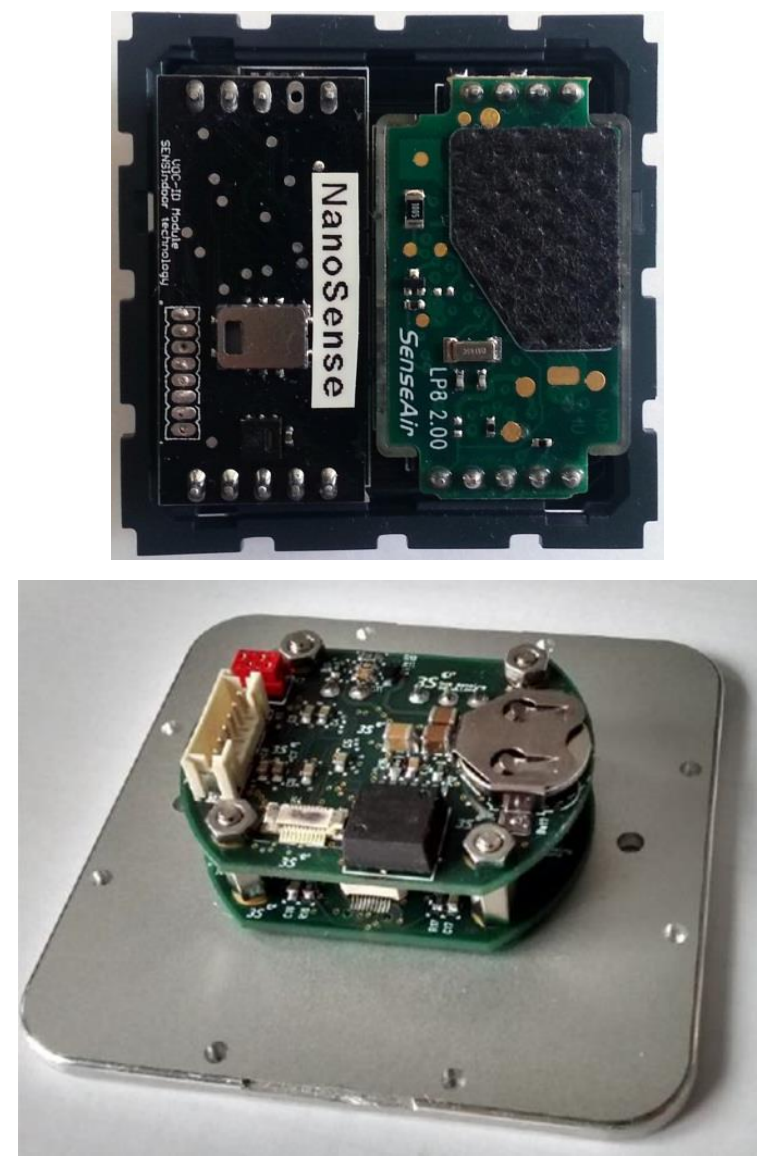

Fig. 6. Highly integrated electronics for sensor operation and read-out with very low Bill of Materials (BOM) by NanoSense (top) and with Al frontplate for integration in standard wall mounts for field testing by $3 S$ (bottom). Both systems also include $\mathrm{CO}_{2}, \mathrm{RH}$ and temperature sensors for comprehensive IAQ control.
A low-cost packaging solution was realized for the novel micro-pre-concentrator ( $\mu \mathrm{PC})$, Fig. 7, and the function was successfully demonstrated for the detection of benzene [4].
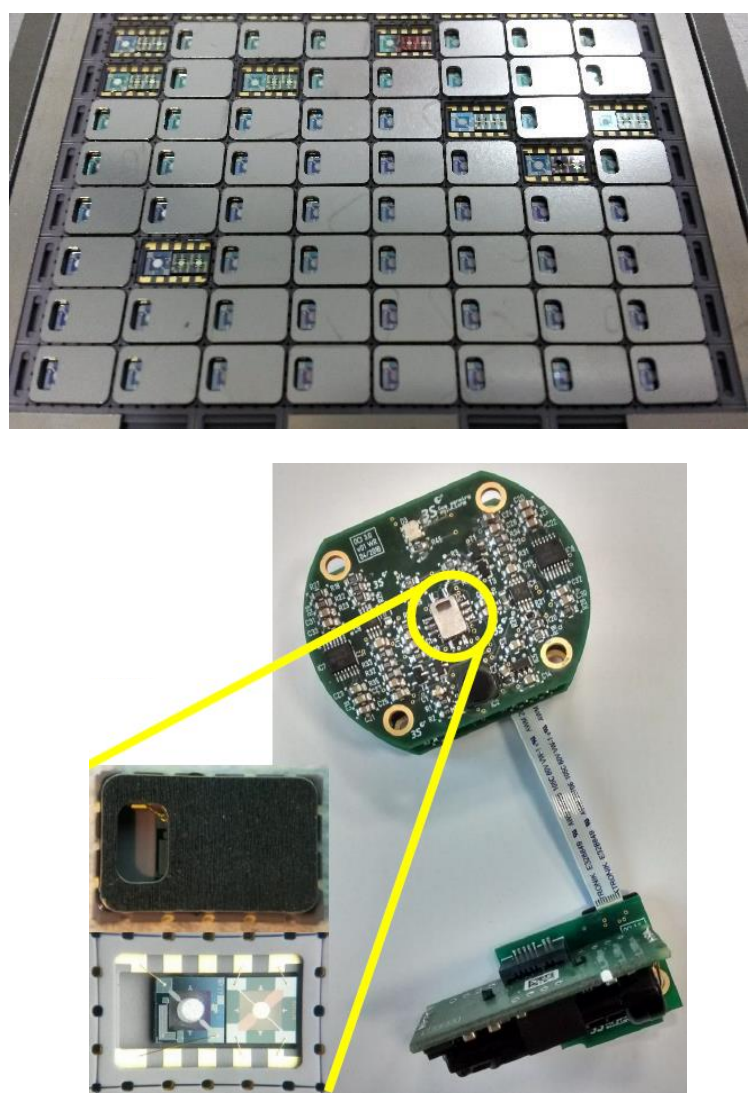

Fig. 7. Mass production compatible low-cost package for $\mu P C$ and dual MOS sensor (top); integrated system with highlighted sensor module (bottom) [11].

In fact, the partners addressed not only aspects as described in the original project plan, but went beyond this, i.e. with two systems supplied for an independent test of benzene detectors carried out by JRC Ispra and with a novel concept for on-site calibration of VOC sensors at ppb levels [12].

\section{Lessons learned}

Beyond the technological results achieved in the project some lessons were learned that are important for the successful initiation and implementation of R\&D projects. First of all, a clear objective and common goals are important to receive funding in today's highly competitive EU (and other) calls. This can best be addressed with a top-down approach when setting up the project. However, team spirit within the project is a very important key for success. Thus, project meetings should also foster personal relationships and encourage team-work. On the other hand, projects bringing together research institutions and industrial partners need to fix clear rules, especially for publications and handling of IPR. Strict procedures should be 
implemented to ensure that everyone working on the project is aware of the rules and adheres to them. Furthermore, helpful ideas often come from unexpected directions so everyone should be aware of the challenges so they can actively contribute with their expertise. One key here is transparent communication within the project to keep all partners in the loop. Finally, everyone within the project should actively contribute to dissemination, not only in scientific publications and at conferences, but also via press releases and publications for the general public - this is highly important especially for finding further partners for commercial exploitation.

To achieve greater visibility, SENSIndoor has teamed up with other EU projects addressing the same application on two occasions: first, we organized a joint booth and special session at SENSOR+TEST, the world's largest fair for sensors and measurement technology in Nuremberg, May 10-12, 2016, together with the projects MSP [13] and IAQSense [14]. Then, we organized a special session "Changing the game in the management of Indoor Air Quality - Real time monitoring for improved health, comfort and energy efficiency" at Indoor Air 2016, Ghent, July 7, 2016 [11]. In this $14^{\text {th }}$ international conference of Indoor Air Quality and Climate with more than 1.000 participants, lowcost sensor technology was a welcome addition to the many contributions focusing on analytical measurements. Both events were highly successful in promoting not only our specific solution but in emphasizing the importance of IAQ for energy consumption and our well-being.

\section{Outlook}

After demonstrating the different technologies and their successful integration within the current project, we are now working together with our partners on the commercialization of the individual technologies and components as well as the overall system. Our dissemination efforts have helped in finding partners for further exploitation for different specific applications.

Beyond SENSIndoor, further targets were identified for IAQ, but also other application fields, i.e. medical, environmental, and industrial. These were compiled in the ESSC roadmap recently presented to the European commission [15].

\section{Acknowledgements}

The SENSIndoor project has received funding from the European Union's Seventh Program for research, technological development and demonstration, grant agreement No 604311.

Multiple input from and valuable discussions with the EuNetAir community (COST Action TD1105) are gratefully acknowledged.

\section{References}

[1] J. Huotari et al.: Pulsed laser deposition of metal oxide nanostructures for highly sensitive gas sensor applications, Sensors \& Actuators B 236 (2016), 978-987, doi:10.1016/j.snb.2016.04.060

[2] D. Puglisi et al.: Exploring the Gas Sensing Performance of Catalytic Metal/Metal Oxide 4HSiC Field Effect Transistors, Materials Science Forum 858 (2016), 997-1000, doi:10.4028/www.scientific.net/MSF.858.997

[3] M. Leidinger et al.: Selective detection of naphthalene with nanostructured $\mathrm{WO}_{3}$ gas sensors prepared by pulsed laser deposition, J. Sens. Sens. Syst. 5 (2016), 147-156, doi:10.5194/jsss-5-147-2016

[4] M. Leidinger et al.: Integrated pre-concentrator gas sensor microsystem for ppb level benzene detection, Sensors \& Actuators B 236 (2016), 988-996, doi:10.1016/j.snb.2016.04.064

[5] N. Helwig et al.: Gas mixing apparatus for automated gas sensor characterization, Meas. Sci. Technol. 25 (2014) 055903 (9pp); doi:10.1088/0957-0233/25/5/055903

[6] M. Bastuck et al.: Exploring the selectivity of $\mathrm{WO}_{3}$ with iridium catalyst in an ethanol/naphthalene mixture using multivariate statistics; Thin Solid Films (2016); doi:10.1016/j.tsf.2016.08.002

[7] C. Bur: Selectivity Enhancement of Gas Sensitive Field Effect Transistors by Dynamic Operation, Dissertation, Linköping University Electronic Press, 2015; doi:10.3384/diss.diva-114670

[8] C. Bur et al.: Discrimination and quantification of volatile organic compounds in the ppb-range with gas sensitive SiC-FETs using multivariate statistics, Sensors \& Actuators B 214 (2015), 225-233, doi:10.1016/j.snb.2015.03.016

[9] T. Baur et al.: Optimierung des temperaturzyklischen Betriebs von Halbleitergassensoren, tm - Technisches Messen, 82 (4) (2015), 187195; doi:10.1515/teme-2014-0007

[10] M. Leidinger et al.: Selective detection of hazardous VOCs for indoor air quality applications using a virtual gas sensor array; J. Sens. Sens. Syst. 3 (2014), 253-263; doi:10.5194/jsss-3-2532014

[11] E. Seitz, C. Iroulart, A. Schütze: Changing the game in the management of Indoor Air Quality Real time monitoring for improved health, comfort and energy efficiency; Proc. Indoor Air 2016, Ghent, Belgium, July 3-8, 2016, summary of session 25, ISBN-13: 978-0-9846855-5-4

[12] C. Schultealbert et al.: A novel approach towards calibrated measurement of trace gases using metal oxide semiconductor sensors, Sensors \& Actuators B 239 (2017), 390-396; doi:10.1016/j.snb.2016.08.002

[13] Multi Sensor Platform for Smart Building Management, http://www.multisensorplatform.eu/

[14] Nanotechnology-based sensors for environmental monitoring, http://www.iaqsense.eu/

[15] Roadmap: Towards European Leadership in Sensor Systems; download at www.cluster-essc.eu/ 